perceive the standard of general practice to have been at a low ebb, the worst advice for a patient with chest pain was reckoned to be "take two aspirins and go to casualty"; nowadays the very best advice is to "take one aspirin and go as fast as possible to the nearest hospital coronary care unit."

Consultant Cardiologist,

M C PETCH

Regional Cardiac Centre, Papworth Hospital,

Cambridge CB3 8RE
1 Rowley JM, Garner C, Hampton JR. The limited potential of special ambulance services in the management of cardiac arrest. Br Heart $\mathcal{F} 1990 ; 64: 309-12$.

2 Gruppo Italiano Per Lo Studio Della Streptochinasi Nell'Infarto Miocardico (GISSI). Effectivenes of intravenous thrombolytic treatment in acute myocardial infarction. Lancet 1986;i:397-402.

3 ISIS-2 Collaborative Group. Randomised trial of intravenous streptokinase, oral aspirin, both, neither among 17,187 cases of suspected acute myocardial infarction: ISIS-2. Lancet 1988;ii:34960.

4 AIMS Trial Study Group. Effect of intravenous APSAC on mortality after acute myocardial infarction: preliminary report of a placebo controlled trial. Lancet $1988 ;$; $: 545-9$.

5 Wilcox RG, von der Lippe G, Olsson CG, Jensen G, Skene AM, Hampton JR. Trial of tissue plasminogen activator for mortality reduction in acute myocardial infarction. Anglo-Scandinavian study of early thrombolysis. Lancet 1988;ii:525-30.

6 O'Donnell M. Battle of the Clotbusters. BMF 1991;302:1259-61.

\title{
What determines the age at the menopause?
}

\section{The number of ovarian follicles seems the most important factor}

The menstrual discharge ceases in most women about their fortieth year; but with those in whom it goes on longer it lasts even to the fiftieth year, and women of that age have been known to bear children. But beyond that age there is no case on record.

Aristotle's assessment was similar to those of Hippocrates and also Roman authors, so it seems that 2000 years ago most women entered the menopause in their early $40 \mathrm{~s} .{ }^{2}$ Mediaeval authors, however, gave the 50 s as the age when menses ceased $^{3}$ - much closer to the timing for twentieth century women.

In the past 100 years data from schoolchildren have shown a steady fall in the age at menarche in industrialised communities. ${ }^{4}$ Has there been a corresponding change in the age at the menopause? Unfortunately, reported surveys of the menopause have suffered from methodological defects. Retrospective interviews underestimate the age at the menopause, as does digit preference when women round up a recollected age to 40,45 , or 50 years. A mean also underestimates the age at the menopause; it would be more accurate to use the median. Even in prospective studies there is no agreement on whether the menopause begins with the last episode of bleeding or after amenorrhoea has been present for nine months or more.

Nevertheless, those studies least subject to bias show a striking agreement that the median age at the menopause is currently around 50 in Western industrialised societies. ${ }^{5}$ In Britain it is $50 \cdot 78,{ }^{5}$ in the United States $49 \cdot 8,{ }^{6}$ and in white South Africans $48 \cdot 7^{7}$ with little apparent change over the past century. In non-European women, however, the menopause seems to occur earlier - in South Africa and the United States black women have an earlier menopause than white women. ${ }^{89}$

What determines the age at which the menopause occurs? For most of the factors claimed to influence the timing the evidence is poor. For example, the common belief that women with an early menarche have a later menopause or the reverse has no factual basis. ${ }^{5}$ Nutrition, however, is important. In New Guinea a group of women with severe prolonged malnutrition and low height and weight had a median age at the menopause of only 43.6 years whereas another group in the same region but with much better nutrition and correspondingly greater height and weight had a later menopause, at $47 \cdot 3$ years. ${ }^{10}$

Parity is linked with menopausal age: nulliparous women have an early menopause, ${ }^{711}$ while increased parity, particularly in the higher social classes, correlates with a later menopause. ${ }^{512}$ One surprising report is that mothers of twins enter the menopause about a year earlier than women who have had singleton infants ${ }^{12}-$ why is not clear. A woman's age at the time of her last pregnancy has also been reported to influence her age at the menopause, women whose last pregnancy occurred before the age of 28 reputedly having an earlier menopause than those with their last pregnancy at a later age. ${ }^{13}$ This could, however, be due to a longer fertile period in the women with later pregnancies. There is also some evidence that blindness may lead to a later menopause. ${ }^{14 a}$

Chronic systemic infections or localised disease of the reproductive system impair fertility, but neither systemic nor genital disease seems to influence the age at the menopause. With the exception of mumps oophoritis, pelvic or systemic infections rarely cause ovarian failure. A familial link associated with partial deletion of the long arm of the $\mathrm{X}$ chromosome has been found in a few cases but not in our series. ${ }^{14 \mathrm{~b}} 14 \mathrm{c}$

One of the few well documented influences on the age at the menopause is tobacco smoking. Women who smoke enter the menopause up to two years earlier than those who do not. ${ }^{15-18}$ The effect seems to be dose related and may be mediated partly through lowered oestrogen concentrations. ${ }^{19-21}$ Studies in rodents have shown that benzpyrene destroys primordial oocytes. The rodent ovary contains an enzyme system metabolising polycyclic aromatic hydrocarbons to cytotoxic, potentially carcinogenic intermediates. ${ }^{22}$ If the human ovary responds similarly this would explain the earlier menopause of cigarette smokers. The aromatic hydrocarbons of cigarette smoke might also accelerate aging of oocytes by increased oxidation of cell membranes as a result of combustion products such as nitrous oxide. ${ }^{23}$

The most important factor determining a woman's age at the menopause is the number of ovarian follicles. Human primordial germ cells separate from somatic cells at an early stage of embryogenesis. Some $1000-2000$ migrate to the gonadal ridge, where they multiply rapidly to a maximum of between five million and seven million follicles around the fifth month of intrauterine life. Multiplication then stops. Thereafter there is a steady loss of primordial follicles from the fetal ovary, so that by the time the baby is born each ovary contains about one million follicles. ${ }^{24} 25$

This number continues to diminish after birth (independently of any cyclic hormonal change or the physiological state of the woman), but fewer than $0.01 \%$ are ovulated; the remainder degenerate. Little is known about the mechanisms responsible, although the observations that follicles fail to grow in anencephalic fetuses ${ }^{26}$ and that in rodents hypophysectomy retards the rate of loss of primordial follicles ${ }^{27}$ show the importance of the pituitary gland. Depletion of ovarian follicles occurs independently of physiological and environmental factors (with the exception of those that actually destroy follicles) until the perimenopausal phase is reached. The rate of loss of primordial follicles then acce- 
lerates, and the menopause occurs when the number of primordial follicles has fallen to a critical number..$^{28}$

The accelerated loss of primordial follicles in the perimenopausal phase occurs in parallel with rising gonadotrophin concentrations. It is not known, however, whether the rate at which ovarian follicular reserve becomes depleted is regulated primarily by factors within the ovary itself or whether the accelerated follicular loss at this stage results from a primary change in the control of gonadotrophins. Nor is the trigger mechanism known, nor what determines the timing of any altered neuroendocrine activity, particularly in the perimenopausal phase. Clearly the timing of the phase of accelerated follicular loss and its speed will determine age at onset of the menopause. Is the date of the menopause genetically "programmed" for each woman or might it be influenced through the neuroendocrine control of gonadotrophin secretion? Could the time at which menopause occurs be altered - forwards or backwards?

Factors such as parity, nutrition, race, and smoking influence the age at the menopause by at most three years either side of the normal median age. Some women, however, have a premature menopause-before the age of 40; in a few it occurs below the age of 30 . Premature ovarian failure is probably much commoner than generally appreciated. In a series of 1001 women under the age of 40 presenting consecutively with amenorrhoea at an endocrine clinic $8 \%$ had never menstruated (primary amenorrhoea) (J Ginsburg et al, fifth international congress on the menopause, 1987). Of the remainder - that is, those with secondary amenorrhoea$9 \%$ had raised gonadotrophin concentrations and were considered to have premature ovarian failure. Seven per cent of this group had plentiful primordial follicles on ovarian biopsy, which suggests resistance to gonadotrophins-the resistant ovary syndrome. No ovarian follicles were found at laparoscopy in the remaining $93 \%$. The cause of premature ovarian failure in the women without ovarian follicles was iatrogenic - the result of chemotherapy or radiotherapy - in $12 \%$ and autoimmune failure in $3 \%$. But in most of those with premature ovarian failure no cause could be found for the absence of ovarian follicles.

In women with premature ovarian failure it is not clear whether fewer primordial germ cells migrate to the germinal ridge in fetal life, whether the rate of multiplication up to the fifth month of intrauterine life is reduced, whether the rate of follicular loss thereafter is greater than normal, or whether there is a combination of all three factors.

Almost all the factors reported to influence the age at the menopause accelerate its onset. Yet if we knew what determined follicular atresia and its accelerated onset in the perimenopausal phase could the process possibly be delayed and the potential store of viable primordial follicles be increased so that the menopause was delayed? Or is the limit set by natural aging processes in the reproductive system as a whole? Either way, knowledge of these factors and how they are integrated could have important implications for both regulating fertility and treating infertility.

JEAN GINSBURG

Consultant Endocrinologist,

Royal Free Hospital,

London NW3 2QG

1 Aristotle: [Historia Animalium] Book VII trans R Creswell. London: George Bell and Sons, 1897 $c 350 \mathrm{BC}$.

2 Amundsen DW, Diers CJ. The age of the menopause in classical Greece and Rome. Hum Biol 1970;42:79-86.

3 Amundsen DW, Diers CJ. The age of menopause in medieval Europe. Hum Biol 1973;45:605-12.

3 Amundsen DW, Diers CJ. The age of menopause in medieval Europe. Hum Biol 1973;45:605-12.
4 Tanner JM. The secular trend towards earlier physical maturation. Tijdschrift voor Sociale Geneeskunde 1966;44:524-39.

5 McKinlay S, Jefferys $M$, Thompson B. An investigation of the age at menopause. $\mathcal{F}$ Biosoc Sci 1972;4:161-73.

6 Treloar AE. Menarche, menopause and intervening fecundability. Hum Biol 1974;46:89-107.

7 Benjamin F. The age of the menarche and certain factors influencing these times. S Afr Med $\mathcal{J}$ 1960;3:316-20.

8 Frere G. Mean age at menopause and menarche in South Africa. $S$ Afr J Med Sci 1971;36:21-4. MacMahan B, Worcester J. Age at menopause: United States. In: US Vital and Health Statistics. 1960-62. Washington DC: Government Printing Office, 1962. (Series I: No 19.)

10 Scragg RFR. Menopause and reproductive span in rural Niugini. Annual Symposium of the Papua New Guinea Medical Society 1973:126-31.

11 Hauser GA, Remen U, Valaer M, Erb H, Mueller T, Obiri J. Menarche and menopause in Israel. Gynaecologia (Basel) 1963;155:38-47.

12 Soberon J, Calderon JJ, Goldzieher JW. Relation of parity to age at menopause. Am $\mathrm{f}$ Obstet Gynecol 1966;96:96-100.

13 Brand PG, Lehert PL. A new way of looking at environmental variables that may affect the age at menopause. Maturitas 1978;1:121-32.

14a Lehrer S. Fertility and menopause in blind women. Fertil Steril 1981;36:396-8.

$14 \mathrm{~b}$ Skibsted L, Westh H, Niebuh RE. X long arm deletions: a review of non-mosaic cases studied with banding techniques. Hum Genet 1984;67:1-5.

$14 \mathrm{c}$ Krauss CM, Durksoy RN, Adkins $\mathrm{L}$, et al. Familial premature ovarian failure due to an interstitial deletion of the long arm of the X chromosome. $N$ Engl J Med 1987;317:125-31.

15 Jick H, Porter J. Relation between smoking and age of natural menopause. Report from the Boston collaborative drug surveillance program, Boston University Medical Center. Lancet 1977; i: 1354-5.

16 Kaufman DW, Slone D, Rosenberg L, et al. Cigarette smoking and age at natural menopause. Am $\mathcal{J}$ Public Health 1980;70:420-2.

17 Andersen FS, Transbol I, Christiansen C. Is cigarette smoking a promoter of the menopause? Acta Med Scand 1982;212:137-9.

18 Adena MA, Gallagher HG. Cigarette smoking and the age at menopause. Ann Hum Biol 1982;9:121-30.

19 Baron JA, Adams P, Ward $M$. Cigarette smoking and other correlates of cytologic estrogen effect in post menopausal women. Fertil Steril 1988;50:766-71.

20 Khaw KT, Tazuke S, Barrett-Connor E. Cigarette smoking and levels of adrenal androgens in postmenopausal women. $N$ Engl f Med 1988;318:1705-9.

21 Longcope C, Johnston CC. Androgen and estrogen dynamics in pre- and post-menopausal women a comparison between smokers and non-smokers. $\mathcal{F}$ Clin Endocrinol Metab 1988;67:379-83.

22 Mattison DR, Thorgeirssom SS. Smoking and industrial pollution and their effects on menopause and ovarian cancer. Lancet 1978; ;:187-8.

23 Tappel AL. Vitamin E and selenium protection from in vivo lipid peroxidation. Ann NY Acad Sci 1980;355:18-29.

24 Block E. Quantitative morphological investigations of the follicular system in women. Acta Anat (Basel) 1952;14:108-23.

25 Baker TG. A quantitative and cytological study of germ cells in human ovaries. Proc $R$ Soc Lond

(Biol) 1963;158:417-33.
26 Baker TG, Scrimgeour JB. Development of the gonad in normal and anencephalic human fetuses. 7 Reprod Fertil 1980;60: 193-9.

27 Jones EC, Krohn PL. The effect of hypophysectomy on age change in the ovaries of mice. f Endocrinol 1961;21:497-508.

28 Richardson SJ, Senikas V, Nelson JF. Follicular depletion during the menopausal transition; evidence for accelerated loss and ultimate exhaustion. I Clin Endocrinol Metab 1987;65:1231-7. 29 Richardson SJ, Nelson JF. Follicular depletion during the menopausal transition. Ann NY Acad Sci 1990;592:13-20.

\section{Physiological importance of nitric oxide}

\section{An endogenous nitrovasodilator}

Since 1867 doctors have prescribed, unwittingly, a class of drug that mimics one of the body's own chemical messengers. One hundred and twenty years after Brunton first gave amyl nitrite for the treatment of angina ${ }^{1}$ it was found that nitric oxide, which is the active component of amyl nitrite, glyceryl trinitrate, and other nitrovasodilators, ${ }^{2}$ is an endogenous mediator. ${ }^{3.5}$ The discovery of the "endogenous nitrovasodilator"356 has clear parallels with the discovery of the endogenous opiates (enkephalins and endorphins) ${ }^{7}$ and, even more recently, with the identification of an endogenous digoxin. ${ }^{8}$

Nitric oxide is synthesised from L-arginine by the vascular endothelium and accounts for the biological activity of the vasodilator endothelium derived relaxing factor. ${ }^{3-5}$ The process is stereospecific and can be inhibited by a variety of analogues of L-arginine, including $N^{\mathrm{G}}$ monomethyl-L- 